
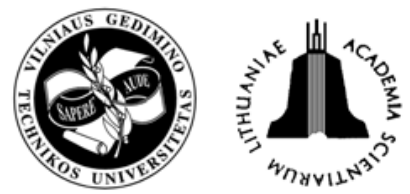

\title{
EVALUATION OF VERACITY OF CAR BRAKING PARAMETERS USED FOR THE ANALYSIS OF ROAD ACCIDENTS
}

\author{
Saulius Nagurnas ${ }^{1}$, Valentinas Mitunevičius ${ }^{2}$, Jan Unarski ${ }^{3}$, Wojciech Wach ${ }^{4}$ \\ 1,2 Vilnius Gediminas Technical University, J. Basanavičiaus g. 28, LT-0322 Vilnius, Lithuania \\ E-mail: ${ }^{1}$ saunag@ti.vgtu.lt, ${ }^{2}$ mv@vta.lt \\ ${ }^{3,4}$ Prof. Dr. Jan Sehn Institute of Forensic Research, ul. Westerplatte 9, Cracow, Poland \\ E-mail: ${ }^{3}$ junarski@ies.krakow.pl, ${ }^{4}$ wach@ies.krakow.pl
}

Received 11 April 2007; accepted 10 September 2007

\begin{abstract}
During the road accident analysis speed of the examined vehicle often is being established in accordance with the length of the trace remained by the vehicle tires. Usually in such case there are values of braking deceleration used for calculations, which are selected from the corresponding references. The real experiment, establishing the braking parameters of the given vehicle, is performed more seldom. In both cases it is important to calculate the vehicle speed in accordance with the received or found values of deceleration as well to estimate the possible limits of the vehicle speed, i.e. to evaluate the veracity of such calculations.
\end{abstract}

This paper presents the results of evaluation of car braking parameters, which are treated as random values in the known probabilistic characteristics.

Keywords: analysis of road accidents, accuracy of calculations, car braking distance, errors, braking parameters, random variables.

\section{Introduction}

One of the main tasks of the road accident analysis is evaluation of the vehicle speed before the road accident. Based on this value the possibility of prevention (by the accident participants) of collision with another vehicle, pedestrian, etc. can be estimated. Because of errors of the accident parameters there arises a question of veracity of results of the analysis.

For evaluation of the motion parameters of the car braking the deterministic mathematical models [1-3] are mostly used. But values of the motion parameters (deceleration of braking or the braking distance) practically are the random quantities. Braking of the same car on the same road for many times does not result in the precisely the same parameter values regardless of attempts to retain the same test conditions.

Therefore for evaluation of the final results it is important to have the knowledge of not only the concrete values of the parameters, but also the distribution laws of the random variables and limits of the parameter values. Then with the help of various mathematical models the accuracy and veracity of the performed calculations can be determined.

Therefore for evaluation of the braking parameter errors of a vehicle the use of more precise mathematical methods, such as statistical-probabilistic [4], method based on stochastic processes [5], method of total differentials [6], Monte Carlo [7], etc. is necessary.

Based on methods of mathematical statistics an original mixed general linear model using the multiple regression for description of inaccuracies of parameter calculations of car braking is presented. This model is created by use of all experimental data. The predicted values of car braking distance are established and together the limits of residual errors are determined.

\section{Experimental research}

The goal of the experimental research is evaluation of car movement parameters in the case of an emergency braking, such as initial speed $v_{a}$, longitudinal deceleration $a_{x}$, and chiefly - the braking distance $S_{s t}$. The experimental results are necessary for creation of the mentioned mathematical model, which is used for prediction of the mean values of the braking distance $\bar{S}_{s t}$ and their errors (see section 3 ).

The experiments were carried out with 10 cars in good working order and average lifetime of 13 years on the horizontal and plane-surface unroughened dry pavement made of asphalt concrete. The pavement microroughnesses were ignored. The cars were being braked with and without the anti-lock braking system (further ABS). All the cars were with the summer tyres. 
Course and conditions of the experimental research:

1. The cars were tested at initial speed of 40,60 and $80 \mathrm{~km} / \mathrm{h}$ (by speedometer indications). In every case after the proper speed was reached, the cars were braked in emergency manner by the hydraulic actuated service brake system (brakes of cars without the ABS were always locked), the brake pedals remained pressed home until the cars were stopped.

2. The experiments were carried out three times for every of the mentioned speed values (i.e. 9 times for every car).

3. The experiments were carried out on the dry and wet asphalt concrete road pavement (in this paper the research results on the dry road pavement are presented).

4. Air pressure in the car tyres was held for time of the experiments in accordance with the producer recommendations for every car.

5. The braking deceleration $a_{x}$ was read and recorded by time steps $t=0.02 \mathrm{~s}$. Fig. 1 illustrates the deceleration graph $a_{x}=f(t)$ for one car without ABS (AUDI 80 made in 1989) and braked on dry road pavement (initial speed $40 \mathrm{~km} / \mathrm{h}$ ).

6. The measurements were performed by a portable decelerometer VZM 100 (Fig. 2).

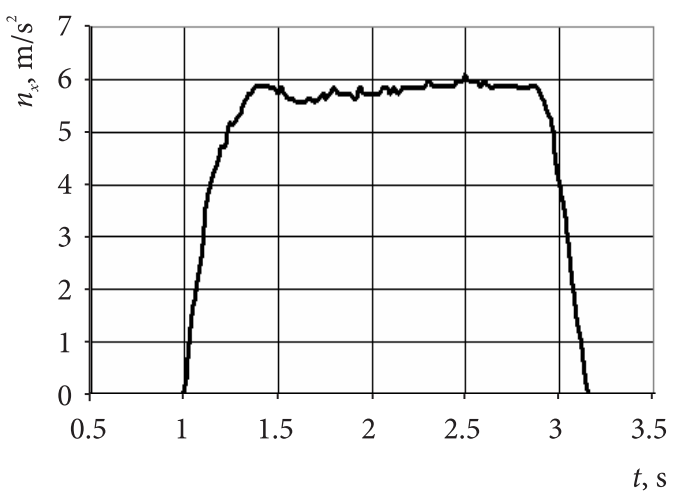

Fig. 1. The braking graph of AUDI $80 \mathrm{car}$

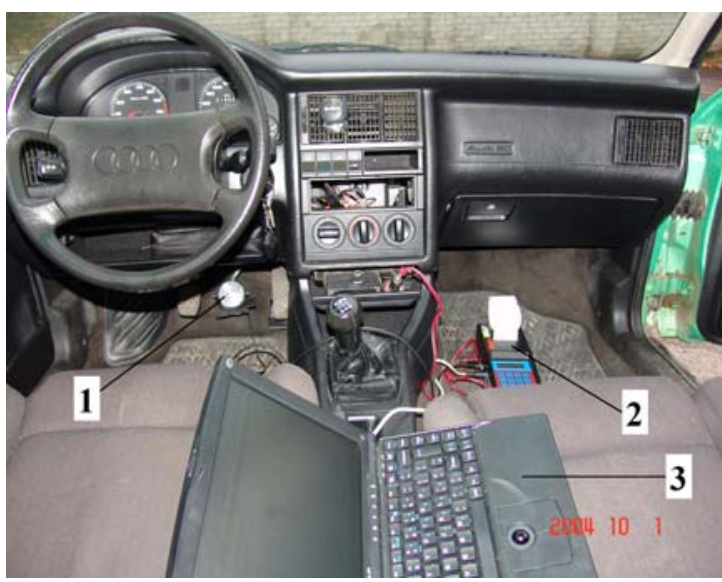

Fig. 2. Location of the experimental equipment inside the car: 1 - sensor of the brake pedal press strength; 2 - decelerometer VZM 100; 3 - the portable computer DELL LATITUDE XPi
7. For every experiment lengths of the braking traces were measured (for cars without ABS) and later their values were compared with calculated ones of the braking distance $S_{s t}$.

8. Integration of the $a_{x}$ dependency function with time (Fig. 1) by the trapezium method [8] enables to obtain true values of car initial speed $v_{a}$ and distances $S_{s t}$ run during the emergency braking.

The experimentally obtained car braking parameters can be interpreted as certain scatter fields of $S_{s t}$ values. For instance, Figs. 3 and 4 show the increase in the scatter "fields“ of $S_{s t}$ values (braking on a dry road pavement).

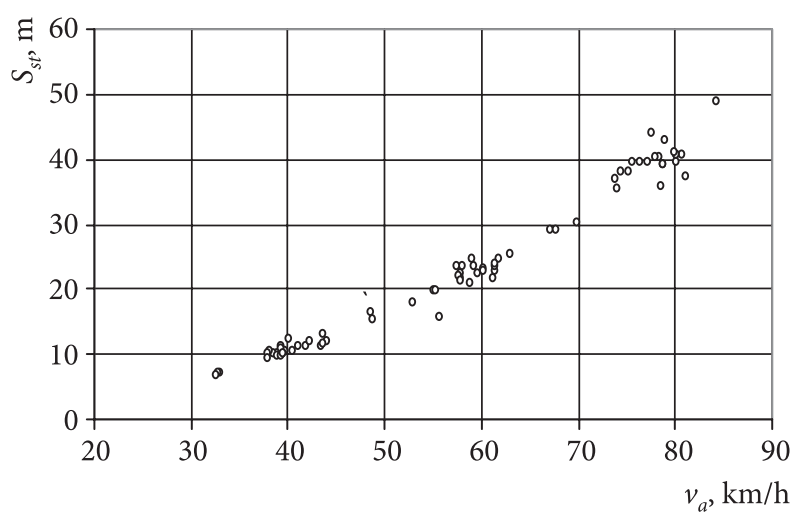

Fig. 3. The character of scatter of $S_{\text {st }}$ values for cars without ABS

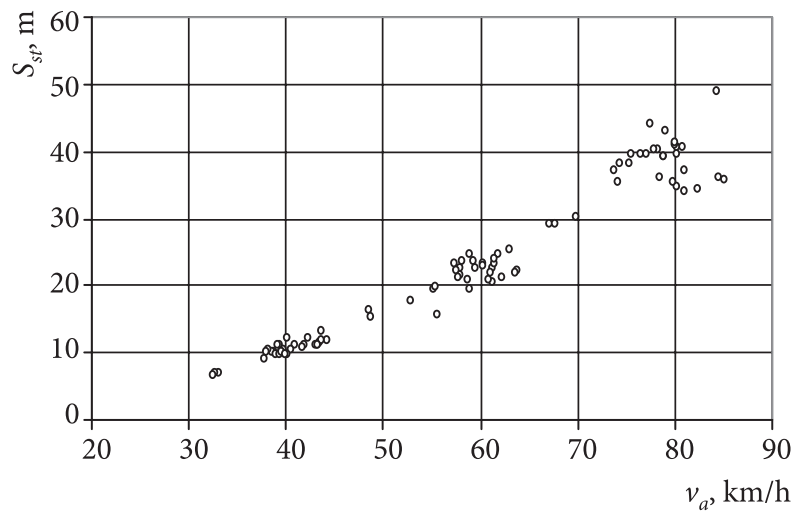

Fig. 4. The character of scatter of $S_{s t}$ values, when cars without/with ABS are evaluated

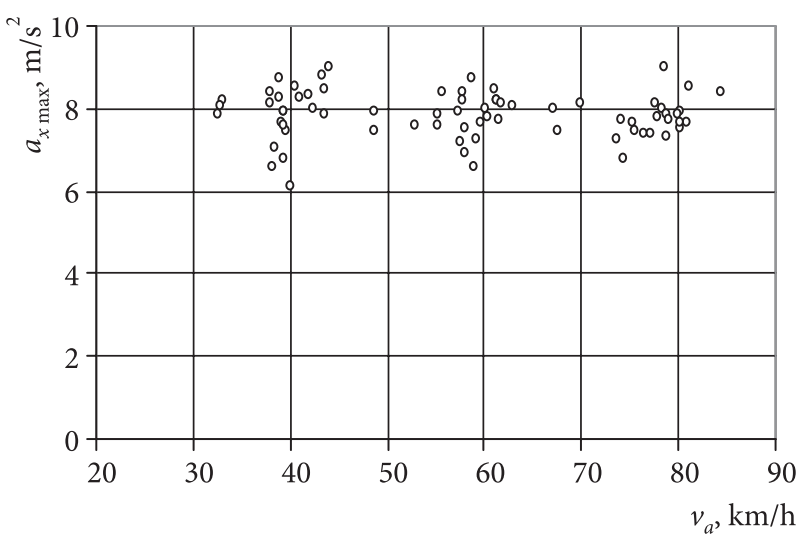

Fig. 5. The scatter of $a_{x \max }$ values for cars without ABS 
Analysis of changes in the longitudinal deceleration $a_{x \max }$ results are presented in the graph in Fig. 5.

The experimental research on car emergency braking showed that increase of the initial car speed $v_{a}$ provokes the increase of scatter field of $S_{s t}$ values. Meanwhile, the longitudinal deceleration $a_{x \max }$ values scatterings are uniform with the corresponding speed values.

It is likely, that would the car motion reach higher speed, the $S_{\text {st }}$ scatter would cover a wide area. It could be explained by the fact, that for the same experimental conditions increase of the initial speed $v_{a}$ provokes the influence of accidental disturbances on the braking process. As examples of such disturbances there could be a slight movement of the steering wheel, a road interval with worse adhesion to the road pavement (a fine sand), etc.

\section{The use of regression analysis for prediction of car braking parameters}

As it is generally accepted today, for creation of models of error estimation of concrete braking parameters (the braking distance $S_{s t}$ ) we used methods of mathematical statistics and experimental research (section 2).

For this purpose there was used a mixed general linear model based on method of multiple regression. It was used for prediction of mean braking distances $\bar{S}_{s t}$ for the tested cars and for determination of limits of residual errors in the form of confidence intervals.

At first, as it was mentioned in section 2, there were calculated values of car deceleration $a_{x}(t), 0 \leq t \leq T$ (Fig. 1), initial speed $v_{a}$ and braking distance $S_{s t}$. Also there were created additional categorical variables, such as "ABS", defining peculiarities of car braking system (if the car has an anti-lock braking system or not), and other variables describing the initial speed of car motion $v_{a}$.

Having these values, values of $\bar{S}_{s t}$ can be predicted corresponding to values of the initial speed $v_{a}$.

With the help of the software pack $S A S$, using the procedure MIXED we carried out the statistical analysis. So created model enables description of influence of determined factors on the variable $S_{s t}$ as well of random ones.

Here we present one example of predictive simulation of $\bar{S}_{s t}$ value, when cars without and with ABS are evaluated (they were braked on a dry road pavement). Calculations performed with the initial data result in the following regression equation:

$$
\begin{aligned}
& \bar{S}_{s t}=0.006345 \cdot v_{a}^{2}+(-0.00158) \cdot v_{a}^{2}+ \\
& 1.8356+e\left(S_{s t}\right),
\end{aligned}
$$

where $e\left(S_{s t}\right)$ - the residual error of the model; in this case it would be the dispersion $D_{s t}$ of the prognosticated value of $\bar{S}_{s t}$.

As we are interested in the average error, we have to find mean square deviation of the $\bar{S}_{s t}$ value: $\sigma_{S s t}=\sqrt{D_{S s t}}$. So we can find the residual errors of the prognosticated

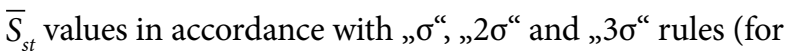
$68.3 \%, 95.4 \%$ and $99.7 \%$ of data reliability accordingly).
Then, remaining only the estimates of the categorical variables we can write the following expression of the equation (1):

$$
\begin{aligned}
& \bar{S}_{s t}=0.006345 \cdot v_{a}^{2}+(-0.00158) \cdot v_{a}^{2}+ \\
& 1.8356+e\left(S_{s t}\right) .
\end{aligned}
$$

Calculations for cars braked on a dry asphalt concrete pavement, will result it the following error values (see Table, Figs. 6, 7).

It is seen from the presented results, that increase of the initial speed $v_{a}$ provokes the increase of absolute values of residual errors of the $\bar{S}_{s t}$ values in the even manner, but the relative values remain almost unchanged.

In other cases of simulation (cars were braked also on other road pavements) increase of the initial speed $v_{a}$

$\bar{S}_{s t}$ values and their residual errors, when cars without/with ABS are evaluated

\begin{tabular}{|c|c|c|c|c|c|}
\hline \multirow{2}{*}{ No } & \multirow{2}{*}{$v_{a}, \mathrm{~km} / \mathrm{h}$} & \multirow{2}{*}{$\bar{S}_{s t}, \mathrm{~m}$} & \multicolumn{3}{|c|}{ Residual errors $\pm \sigma_{S_{s t}}$ of $\bar{S}_{s t}$} \\
\cline { 4 - 6 } & & & $\sigma$ & $2 \sigma$ & $3 \sigma$ \\
\hline 1 & 40 & 9.460 & 5.1 & 9.7 & 13.9 \\
\hline 2 & 60 & 18.99 & 6.1 & 11.5 & 16.3 \\
\hline 3 & 80 & 32.33 & 5.5 & 10.5 & 14.9 \\
\hline
\end{tabular}

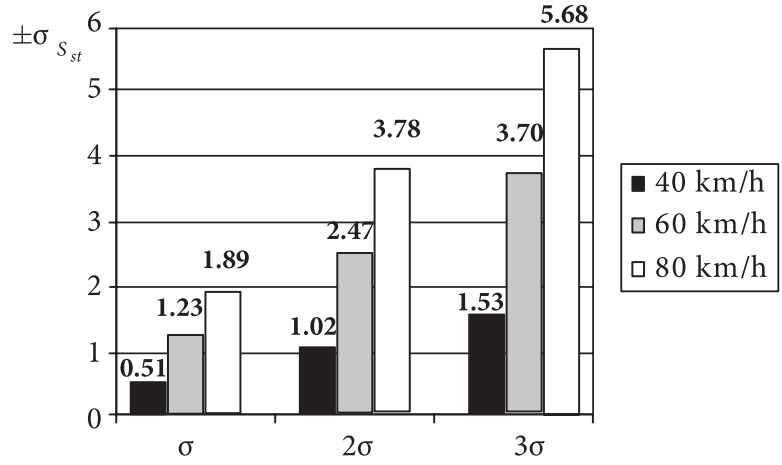

Fig. 6. Mean square deviations in accordance with " $\sigma$ ", " $2 \sigma$ " and " $3 \sigma$ " rules from the prognosticated values of $\bar{S}_{s t}$, when cars without/with ABS are evaluated

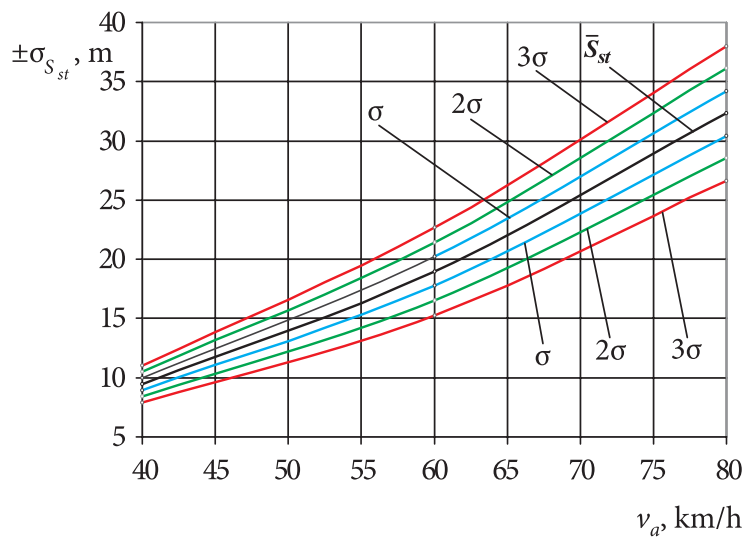

Fig. 7. Dependence of mean square deviations from prognosticated $\bar{S}_{s t}$ values on the car speed, when cars without/with ABS are evaluated 
also provokes a constant increase of absolute values of $\sigma_{S_{s t}}$ especially at higher speed.

Analysis of the experimental results showed, that experimental values of braking distance $S_{s t}$ correspond to the limits of values, calculated using the created mathematical model (Fig. 8). So, this model is usable in the praxis of road accident examination.

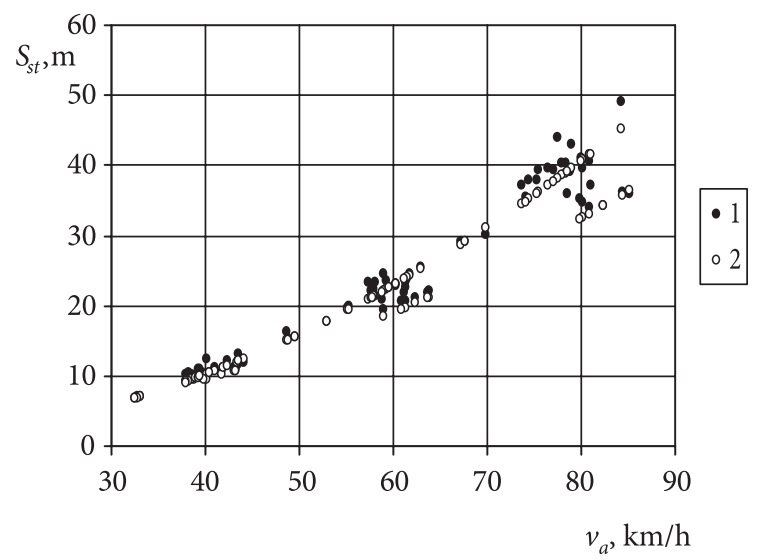

Fig. 8. Scatter of $\bar{S}_{s t}$ values: 1 - experimental values; 2 - prognosticated values

As the calculated values of braking distance $\bar{S}_{s t}$ have a direct reference to the values of deceleration $a_{x}$, so the conclusions about veracity of calculation of the braking distance values in principle are valid also for the mean values of the braking decelerations $\bar{a}_{x}$.

\section{Proposal of application in Monte Carlo simulation}

The idea of the Monte Carlo simulation method is that the pseudo-random numbers generator selects a random value of each input parameter, assuming an a priori given uncertainty range [7]. The Monte Carlo method typically is applied to an existing, deterministic mathematical model of a physical system. Monte Carlo algorithm randomly and systematically executes the model and determines the results of the simulation for a large number of randomly selected input parameters.

The calculations are performed at least several hundred thousands of times, due to which the calculation result is given as a probability distribution, usually in the bell-curve shape, which excellently facilitates interpretation of results.

In the Monte Carlo method it is assumed that the input parameters are statistically uncorrelated and the statistical distribution of the input parameters must be known or assumed - the data can be selected according to different distributions, e.g. uniform, or Gauss. The authors of [9] point out that the majority of typical measurements taken by the police officers in the place of collision corresponds to normal distribution. Values of many parameters were not measured directly but taken from tables, e.g. driver's response time, lag time, pedestrian's velocity, friction coefficient. The values can frequently be adopted as normal distribution [9].
The proposed method enabled to applying of parameterized normal probability density function instead of uniform distribution and use them as input data in Monte Carlo simulation of vehicle crash [10] or pedestrian accident [11].

\section{Conclusions}

1. The absolute values of the mean square deviations $\sigma_{S_{s t}}$ of the braking distance increase, if the initial speed $v_{a}$ increases, especially at higher speed.

2. The relative values of the mean square deviation $\sigma_{S_{s t}}$ of the braking distance remain almost constant, if the initial speed $v_{a}$ increases. Simulation of braking parameters (when cars without/with ABS are evaluated) resulted in the following limits of the $\bar{S}_{s t}$ veracity (experimental conditions - dry asphalt concrete pavement): for $v_{a}=40 \mathrm{~km} / \mathrm{h}$ the limits are $\bar{S}_{s t} \pm 5.1 \%$, for $v_{a}=60 \mathrm{~km} / \mathrm{h}-\bar{S}_{s t} \pm 6.1 \%$ and for $v_{a}=$ $80 \mathrm{~km} / \mathrm{h}-\bar{S}_{s t} \pm 5.5 \%$ (for $68.3 \%$ of data reliability in accordance with the " $\sigma$ " rule).

3. The presented examples of calculations show that intervals of the results scatter can be rather wide. Especially it ought to be emphasized if we want to seek maximum accuracy, i.e. the resulting value (here - braking distance $\bar{S}_{s t}$ ), if estimated according to " $2 \sigma$ " and " $3 \sigma$ " rules. The magnitude of such deviations can essentially influence the results of calculations and the evaluation of road situation close before the road accident.

4. The proposed method enabled to applying of parameterized normal probability density function instead of uniform distribution and use them as input data in Monte Carlo simulation of vehicle crash or pedestrian accident.

\section{References}

1. LUKOŠEVIČIENĖ, O. The road accident analysis and simulation: monograph (Autoịvykių analizè ir modeliavimas: monografija). Vilnius: Technika, 2001. 244 p. (in Lithuanian).

2. NOON, R. Engineering analysis of vehicular accidents. Boca Raton: CRC Press, 1994. 239 p.

3. ILARIONOV, V. A. et al. The traffic regulations and foundations of the safe car driving (ИЛАРИОНОВ, В. А. и др. Правила дорожного движения и основы безопасного управления автомобилем). Moscow: Transport, 1997. 446 p. (in Russian).

4. ILARIONOV, V. A. The examination of road accidents (Экспертиза дорожно-транспортных происшествий). Moscow: Transport, 1989. 255 p. (in Russian).

5. GUZEK, M. Analysis of the rectilinear braking as a stochastic process (Analiza prostoliniowego hamowania samochodu jako procesu stochastychnego). In Proceedings of the Politechnika Swietokrzyska. Mechanika. Kielce, 2000, Vol. 71, p. 147-156 (in Polish). 
6. DANNER, M.; HALM, J. The technical analysis of road accidents (Technische Analyse von Verkehrsunfaellen). Eurotax (International) AG, 1994. 570 p. (in German).

7. WOOD, D.; O'RIORDAIN, S. Monte Carlo simulation methods applied to accident reconstruction and avoidance analysis. SAE Paper 940720.

8. KVEDARAS, B.; SAPAGOVAS, M. Methods of calculations (Skaičiavimo metodai). Vilnius: Mintis, 1974. 516 p. (in Lithuanian).

9. BARTLETT, W.; WRIGHT, W.; MASORY, O.; BRACH, R.; BAXTER, A.; SCHMIDT, B.; NAVIN, F.; STANARD, T. Evaluating the uncertainty in various measurement tasks common to accident reconstruction. Special Publication Accident Reconstruction SP-1666 (2002), SAE Paper No. 2002-01-0546.

10. WACH, W.; UNARSKI, J. Determination of vehicle velocities and collision location by means of Monte Carlo simulation method. SAE Special Publication SP-1999 Accident Reconstruction 2006, SAE Technical Paper 2006-01-0907.

11. WACH, W.; UNARSKI, J. Uncertainty analysis of the preimpact phase of a pedestrian collision. SAE Special Publication SP-2063, Accident Reconstruction 2007, SAE Technical Paper 2007-01-0715. 